\title{
Usage, definition, and measurement of coexistence, tolerance and acceptance in wildlife conservation research in Africa
}

\author{
Jillian Knox, Kirstie Ruppert, Beatrice Frank, Carly C. Sponarski, \\ Jenny Anne Glikman
}

Received: 14 January 2020/Revised: 27 April 2020/Accepted: 27 May 2020/Published online: 15 June 2020

\begin{abstract}
The terms 'coexistence', 'tolerance,' and 'acceptance' appear frequently in conservation literature, but lack consistent characterization, making them difficult to apply across intervention frameworks. This review aims to describe the common characterizations of these three terms using Africa-based research as a case study. Through systematic lexical searches, we identified 392 papers containing one or more of the three terms. We assessed their usage, definition, and measurement (or lack thereof) in wildlife conservation. Coexistence was used in $46 \%$ of papers, but was defined in only $2 \%$ and measured in $4 \%$. Tolerance and acceptance were used in $63 \%$ and $61 \%$ of the papers in which they appeared, respectively, defined in $4 \%$ and $2 \%$, and measured in $19 \%$ and $5 \%$. These results confirm the lack of clear understanding of these concepts and evidence the need for a precise lexicon. This would allow conservationists to cohesively describe their work and increase replicability of research across contexts.
\end{abstract}

Keywords Attitudes - Behavior - Conservation goals · Conservation lexicon H Human dimensions .

Literature review

\section{INTRODUCTION}

The role of humans in wildlife conservation is widely evident and recognized (Cortés-Avizanda et al. 2018), and insights from social science are increasingly used to describe interactions and relationships between humans, wildlife, and ecosystems (Bottrill et al. 2014; Bennett 2016;

Electronic supplementary material The online version of this article (https://doi.org/10.1007/s13280-020-01352-6) contains supplementary material, which is available to authorized users.
Bennett et al. 2017). At the same time, a cohesive and precise lexicon of terms related to the human dimensions of conservation-which would allow conservation scientists to describe and share their work-has yet to be developed.

One aspect of wildlife conservation frequently discussed from a social science standpoint is the social dimensions of human-wildlife relationships. Interactions between humans and wildlife are often described in terms of conflict and coexistence. Human-wildlife conflict has been studied extensively (Nyhus 2016; Hill 2017; Songhurst 2017) and is well characterized in conservation literature (Madden 2004; Inskip and Zimmerman 2009; Peterson et al. 2010; Redpath et al. 2015). However, fewer efforts have been made to describe and operationalize the concept of humanwildlife coexistence, despite an exponential increase in the term's use in scientific papers over the past 20 years (Frank 2016; Nyhus 2016; Frank and Glikman 2019). The word 'coexist' has two distinct dictionary definitions: to live in peace with each other or to exist in the same place or at the same time ('coexist', Merriam-Webster ${ }^{1}$ ). In conservation, the meaning of coexistence is often implicit (Frank et al. 2019), and its connotation can differ among conservationists (Treves et al. 2009; Harihar et al. 2013; Carter and Linnell 2016).

We investigated the use of the term coexistence, as well as two related terms, tolerance and acceptance, in wildlife conservation research in Africa. The term 'tolerance' is the "the action of bearing hardship, or the ability to bear pain or hardship" ('tolerate', Merriam-Webster ${ }^{2}$ ), while the term 'acceptance' refers to endurance "without protest or reaction" ('accept', Merriam-Webster ${ }^{3}$ ). These terms

\footnotetext{
${ }^{1}$ https://www.merriam-webster.com/dictionary/coexist.

${ }^{2}$ https://www.merriam-webster.com/dictionary/tolerate.

${ }^{3}$ https://www.merriamwebster.com/dictionary/accept.
} 
(tolerance and acceptance) are used in conservation as a means of different perceived abilities of sharing landscape with wildlife. We focused our literature review on wildlife conservation research in Africa for several reasons. The continent encompasses around a quarter of global biodiversity, including the earth's largest intact collection of large mammals. In 2016, the Division of Environmental Law and Conventions of the United Nations Environmental Programme recommended implementing conservation actions on a greater scale to avoid further biodiversity loss in Africa. The report proposed strategies such as strengthening trans-boundary conservation actions, implementing the outcomes of conferences, and increasing awareness of the contribution of wildlife conservation to people's lives; all of which require conservation researchers, managers, and organizations to describe and share results with each other and with a broader audience (UNEP-WCMC 2016). However, to share findings and conclusions efficiently, common and agreed-upon definitions of the key concepts in wildlife conservation are needed. With growing human populations and a rising number of shared landscapes, concepts like coexistence, tolerance, and acceptance will become increasingly prevalent in wildlife conservation efforts in Africa. This will be even more relevant as interactions between humans and wildlife are increasing across Africa (Hoare 1995; Tchamba 1995; Madden 2004). Furthermore, conservation research in Africa plays a significant role in generating knowledge and strategies for wildlife conservation (Child et al. 2012; de Pinho et al. 2014; Benjamin-Fink and Reilly 2017) in a diversity of landscapes (Myers et al. 2000). Understanding how these key terms are currently characterized and identifying gaps in usage, definition, and measurement is essential to make sure these terms are applied consistently in conservation in Africa and across the globe.

We identified tolerance and acceptance as key terms because both are frequently used when discussing maintaining or increasing species populations (Bruskotter et al. 2015) or measuring the capacity of humans to live with a species (Hill and Webber 2010; Hazzah et al. 2013; Carter and Linnell 2016). Two parallel lines of inquiry on acceptance of and tolerance for wildlife have been employed to understand behaviors aimed at living with or eradicating wildlife (Bruskotter and Fulton 2012; Bruskotter et al. 2015; Kansky et al. 2016). Some researchers use the two terms synonymously (Bruskotter and Wilson 2014; Treves and Bruskotter 2014; Inskip et al. 2016; Western et al. 2019), referring to Bruskotter and Fulton's (2012) definition of tolerance as the passive acceptance of a wildlife population. Others see these terms as disjointed and use different measures to assess tolerance and acceptance (Frank et al. 2019). Parallel to the duality of definitions, tolerance is generally conceptualized and measured in two forms: attitudes and behaviors (St John et al. 2012; Bruskotter and Wilson 2014; Frank et al. 2019). Research on acceptance has primarily focused on the extent to which individuals are willing to accept different levels of local wildlife populations (Decker and Purdy 1988; Carpenter et al. 2000; Riley and Decker 2000; Lischka et al. 2008).

In this contribution, we attempt to start to answer the primary research question:

What do coexistence, tolerance, and acceptance mean (in terms of usage, definition and measurement) and how are these concepts used in wildlife conservation research in Africa?

\section{METHODS}

We conducted a systematic literature search with the aim to provide a representative picture of how the terms coexistence, tolerance, and acceptance are currently used, defined, and measured in published literature on wildlife conservation in Africa. This review should reveal the commonalities and information gaps (Haddaway et al. 2015) associated with the usage of the three terms in literature related to wildlife conservation in Africa, including the current state, geographical distribution, and chronological spread. We also compare definitions and measurements, or lack thereof, of the key terms within wildlife conservation research in Africa, and particularly the ways in which coexistence is conceptualized when used as a goal of conservation efforts.

\section{Literature search}

Between January and April of 2018, we conducted a systematic literature search using both Google Scholar and ISI Web of Science (Haddaway et al. 2015), both of which cover natural as well as social sciences. The search aimed to capture available evidence relevant to our research question from published sources. We followed the recommendations of Haddaway et al. (2015) for maintaining quality and reliability in a traditional literature review by incorporating elements of systematic review methodology (i.e., systematic searching, screening, and critical appraisal).

We selected search terms with the goal of producing a representative sample of wildlife conservation research in Africa in which the three key terms were used, including phrases such as "human dimensions" and "Africa." The search string was developed using terms common in human dimensions of wildlife management (Decker et al. 2012) 
and by examining search terms and strings from similar reviews (Bottrill et al. 2014; Roe et al. 2015; Hanaček and Rodríguez-Labajos 2018). Search criteria included psychological terms such as "motivate" and "attitude" to capture papers on wildlife ecology, management, or conservation in which psychological terms were used. Complete records identified through database searching including all search strings and the number of results each generated can be found in the Supplementary Material (Table S1). Results from the first 100 pages of Google Scholar and of Web of Science were included. The "100 page" limit was not applied to Web of Science in any search due to its smaller subset of papers.

After recording the database hits based on the search string and removing duplicates, we vetted the papers using specific inclusion/exclusion criteria. To be included, papers had to be related to wildlife conservation, cover research conducted in Africa, and be published in a peer-reviewed publication. We included papers containing research from several places if one or more were located in Africa. We included primary research, reviews, and perspectives if published in peer-reviewed journals. We did not apply a date restriction to the potential pool of peer-reviewed research articles, but did restrict the search and therefore inclusion criteria to English publications due to resource constraints.

\section{Lexical search for key terms}

We searched the 740 selected papers for the lemma terms "acceptance, "tolerance", and "coexistence," and their respective lexemes using a MAXQDA 2018 lexical search (VERBI Software 2017). A lexeme is a set of all forms of a term that have the same meaning; the lemma term is the particular form chosen by convention to represent the lexeme (e.g., the lexeme for tolerance includes tolerable, tolerant, and so on). For the remainder of this paper, the three lexemes are represented by the lemmas coexistence, tolerance, and acceptance. We disregarded terms found in the references or journal and publishing information. The original pool of 740 papers was reduced to 392 papers containing one or more instance of one or more key terms using the lexical search results. This final pool was considered in the following analyses.

\section{Data analysis}

\section{Data extraction}

We extracted information from the included papers and organized it in a Microsoft Excel file within the following categories: first author, title, journal, document type, place, focal species (when applicable), year of publication, and use of each key term, and the number of instances of each term in the paper (if applicable). We measured the frequency of each key term (binary) over time using the papers' publication dates. For all 392 papers, each sentence that included a key term was extracted using MAXQDA 2018 (VERBI Software 2017) to understand how the terms were used, defined, and measured.

\section{Coding}

We coded the 392 papers selected during the lexical search according to their inclusion of each key term using a binary scale of 1/0 (yes/no). Each paper was coded by the terms it contained, to signify one or more instance of acceptance (A), coexistence $(\mathrm{C})$, and tolerance $(\mathrm{T})$ in that paper (Fig. 1). Codes A, C, and T were recorded as separate columns in the Excel document.

Next, we examined the extracted sentences containing key terms manually, by term, and coded papers as 'Defined' in the context of that term (e.g., T/Defined) only if a clear and direct definition was given (rather than an implied definition via measurement such as 'tolerance $=$ number of animals killed') (Fig. 1). We recorded all definitions of key terms, organized by paper, in a table format for comparison. If a paper's extracted sentences suggested but did not confirm definition or lack thereof, we manually examined the paper in full. We manually examined all papers flagged as 'Defined' in their entirety to confirm coding accuracy. Two researchers, including the lead author of this review, coded papers. We conducted an intercoder reliability test using a random sample of 40 papers (about 10\%) of the 392 papers selected. We assessed intercoder reliability using Krippendorff's $\alpha$ coefficient $(2004,2007)$, using a minimum accepted value of 0.80 . We used this verification process for each subsequent code (e.g., measurement) to ensure coding consistency and accuracy according to inclusion/exclusion criteria.

We coded all sentences containing key terms that suggested measurement of the term in the study as 'Measured' in the context of that term (e.g., A/Measured) and conducted the same confirmation process as with those marked 'Defined' (Fig. 1). We categorized terms as 'Measured' if they represented variables being quantified in primary research papers or variables with clearly defined specific measurement parameters described in reviews or perspective papers discussing their original research study.

\section{Comparing measurements}

As suggested by social science literature (St John et al. 2012; Bruskotter and Wilson 2014; Frank et al. 2019), we sorted T/Measured papers into two broad categories, attitudes or behaviors toward wildlife and wildlife 


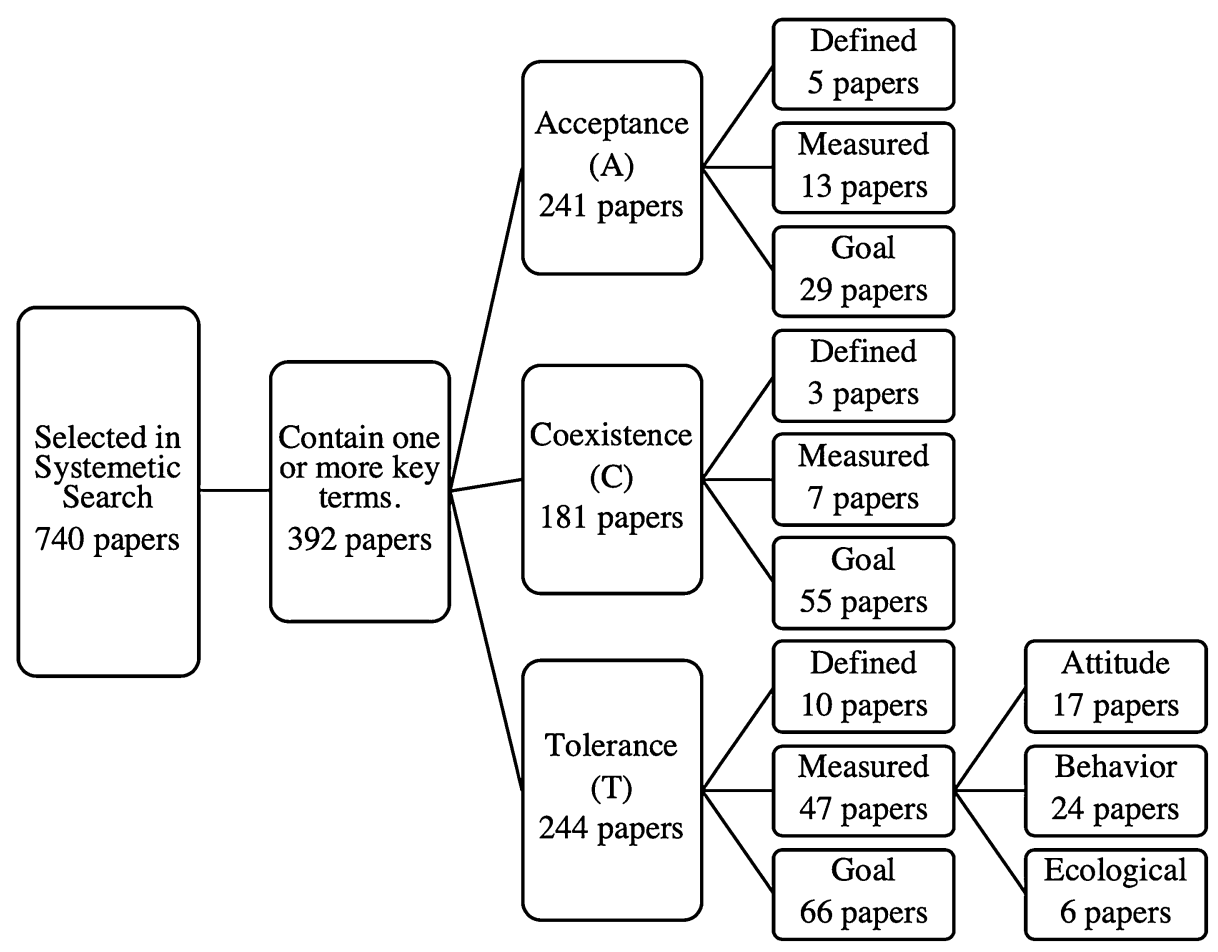

Fig. 1 Hierarchy of coding, with corresponding number of papers coded as each category

management. Papers were coded as 'T/Measured/Attitude' and 'T/Measured/Behavior,' respectively, based on the variables used to quantify tolerance. Papers that used an ecological definition of tolerance, which is defined as an organism's capacity to survive a given factor (Lynch and Gabriel 1987), we coded as 'T/Measured/Ecology.' To identify and categorize measurement variables, we read papers coded 'T/Measured' in their entirety and noted the ways in which tolerance was measured in a Microsoft Excel file.

For all three terms, we assessed how the exact item was being measured in each paper (e.g., willingness to coexist or acceptability of conservation actions). These measurements, along with supporting text, can be found in the Supplementary Material (Tables S3, S6, S9).

\section{Conservation goals}

In broad terms, goals are generalized statements about desired end-states (Elliot and Fryer 2013) or the aim of behavior (Elliot and Thrash 2001). If the papers contained coexistence, tolerance and/or acceptance and indicated that the key term was a goal of current or future conservation research and interventions, such papers were coded as 'Goal' in the context of that term (e.g., T/Goal), and confirmed using the same methodology as definitions and measurements (Fig. 1). To better characterize those instances where coexistence, tolerance, and/or acceptance were identified as goals of current or future conservation efforts, we examined the syntactic context (Tabossi 1988). For each key term, we compiled all sources coded as 'Goal' into a table in Microsoft Word and the exact phrasing of the goal was noted in the Supplementary Material (Table S4).

We coded papers in which key terms appeared but were not defined, measured, or described as a goal simply according to term. For example, a paper in which the term tolerance appeared but was not defined, measured, or described as a goal was coded 'T.'

\section{RESULTS}

\section{Geography and species}

The 392 papers that included coexistence, tolerance, and acceptance covered a range of species and locations (Fig. 2). Most commonly, papers covered research on multiple species $(n=151,38 \%)$, elephants (Loxodonta africana, $n=52,13 \%$ ), lions (Panthera leo, $n=42,11 \%$ ), leopards (Panthera pardus, $n=28,11 \%$ ), or multiple carnivores $(n=27,7 \%)$.

In the papers identified, research was most often conducted in Kenya $(n=62,16 \%)$, South Africa $(n=54$, 


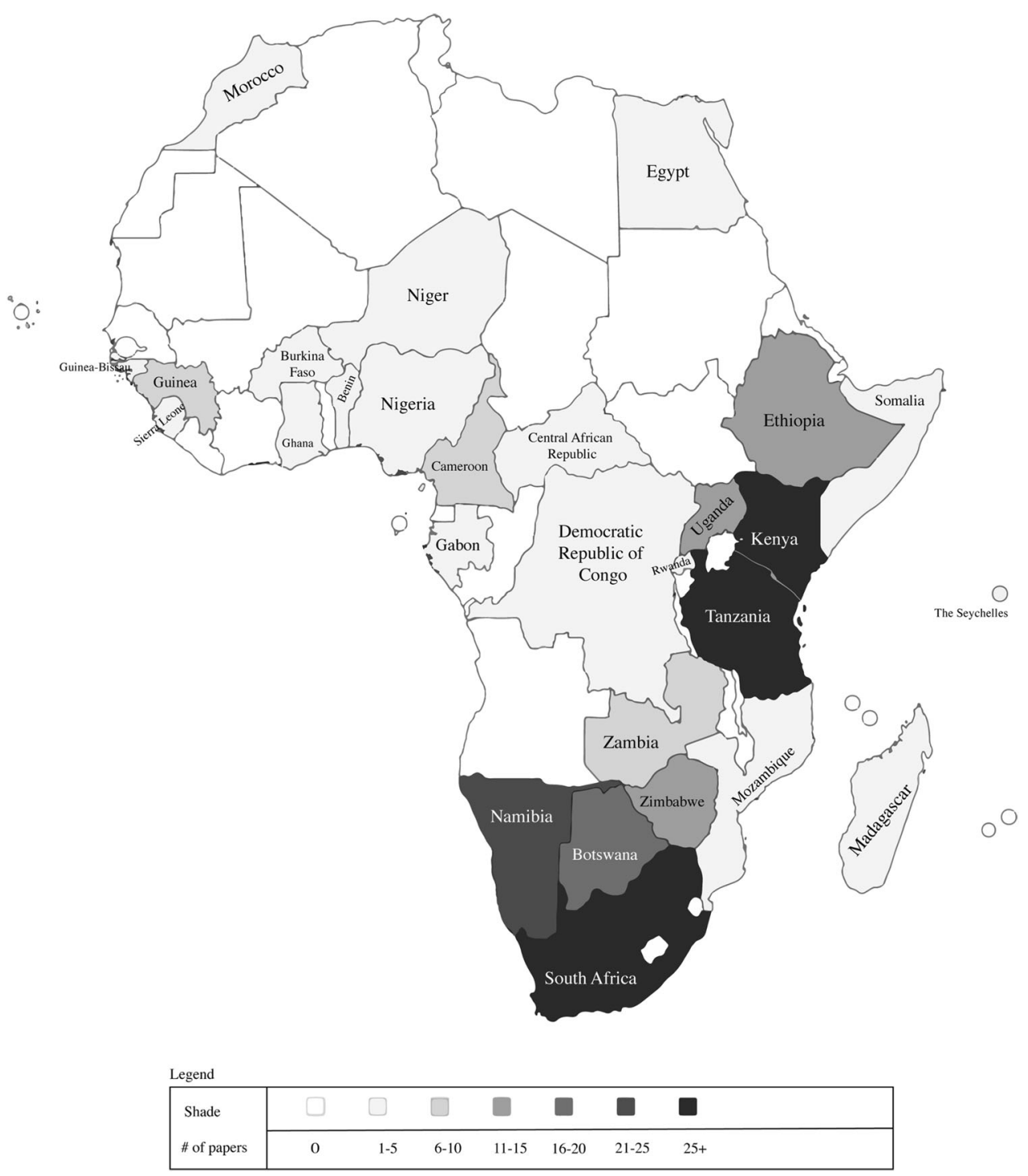

Fig. 2 A frequency map of all the labeled countries in Africa of papers used in this review that contained one or more of the key terms

$14 \%)$, Tanzania $(n=41,10 \%)$, Namibia $(n=24,6 \%)$, and Botswana $(n=20,5 \%)$ (Fig. 2). Many papers covered research in other continents in addition to Africa $(n=71$, $18 \%$ ) or spoke broadly about human dimensions research in Africa $(n=35,9 \%)$.

Table 1 Key term frequencies within 392 papers (including average number of key terms per paper)

\begin{tabular}{llll}
\hline & Coexistence & Tolerance & Acceptance \\
\hline Number of papers & 181 & 244 & 241 \\
Number of mentions & 544 & 1114 & 736 \\
Mean & 1.39 & 2.84 & 1.88 \\
SD & 3.24 & 6.40 & 3.41 \\
Min-max & $0-34$ & $0-70$ & $0-37$ \\
\hline
\end{tabular}

\section{Term usage and chronological trends}

Of the 392 papers that mentioned one or more key terms, $181(46 \%)$ included the term coexistence, $244(62 \%)$, included the term tolerance, and $241(61 \%)$ included the term acceptance (Table 1).

The use of all three key terms increased over time, from 1980 to 2018 (Fig. S1). In general, tolerance and acceptance co-occurred in more papers than either term co-occurred with coexistence (Fig. 3). 63 (16\%) Papers used all three terms.

\section{Coexistence}

Overall, the term coexistence was in 181 out of the 392 papers retrieved $(46 \%)$. It was clearly defined only in 3 (2\%, Fig. 1; Table S2). Of those three, one defined the term 


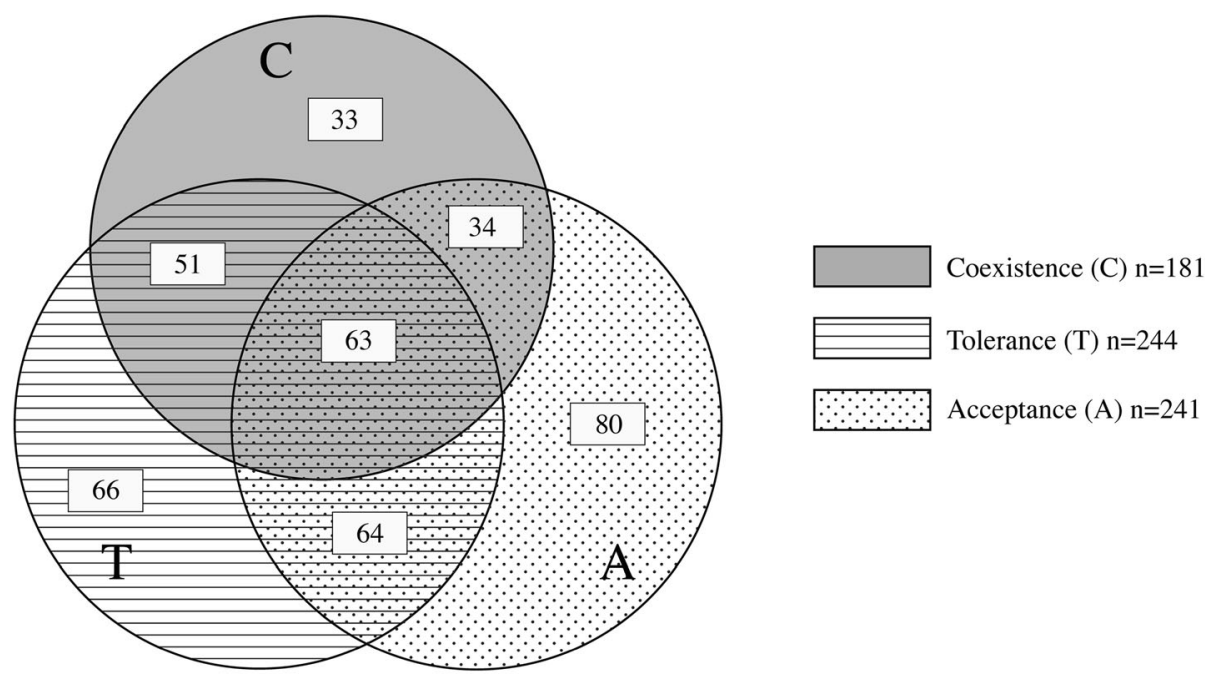

Fig. 3 A Venn diagram illustrating the overlap in term usage between papers $(n=392)$

in the context of a Landscape of Coexistence (Oriol-Cotterill et al. 2015) and the other in the context of payments to encourage coexistence (Dickman et al. 2011) (Table S2). Carter and Linnell (2016) provided a definition of the term coexistence alone, in the context of large carnivores in shared landscapes:

Dynamic but sustainable state in which humans and large carnivores co-adapt to living in shared landscapes where human interactions with carnivores are governed by effective institutions that ensure longterm carnivore population persistence, social legitimacy, and tolerable levels of risk (p. 575).

Few papers $(n=7,4 \%)$ measured coexistence. Among the concepts measured were physical co-occurrence (Hoare and Du Toit 1999; Du Toit 2002), perceptions about ability to coexist (Tessema et al. 2010; Eshete et al. 2015; McNutt et al. 2017), and willingness to coexist with wildlife (Gusset et al. 2009). None of the papers that measured coexistence offered a definition for the term (Table S3).

Coexistence was described as a conservation goal ( $\mathrm{C} /$ Goal') in 55 (30\%, Fig. 1) of 181 papers. The syntactic context of the goal in which the term was used for each paper revealed several commonly used phrases: 16 papers mentioned promoting coexistence, 5 achieving coexistence, 4 enabling coexistence, and 4 fostering coexistence. Of the 55 papers describing coexistence as a goal, 2 defined the term and 3 measured it (Tables S2, S3, S4).

\section{Tolerance}

The term tolerance was used in 244 out of the 392 papers retrieved (63\%, Fig. 1). Of the 244 papers, it was clearly defined in 10 (4\%) (full definitions in the Supplementary Material, Table S5).

Tolerance was measured in 47 of 244 papers (19\%, Fig. 1), 9 of which also defined the key term. Overall, 17 papers used attitudinal measurements to assess tolerance, 24 behavioral measurements, and 6 ecological markers. As a quantitative variable, tolerance was often described by its measurements. Subcategories of attitudinal and behavioral tolerance measurements are listed in Table 2.

Tolerance was described as a conservation goal in 67 of 244 papers (27\%, Fig. 1). Of the 67 papers referring to tolerance as a goal, 5 provided a definition of tolerance as a goal, 21 measured it as a goal, and in 4 cases the authors both defined and measured tolerance as a goal. The specific context for each source can be found in the Supplementary Material (Table S7).

\section{Acceptance}

The term acceptance was used in 241 out of the 392 papers retrieved $(61 \%$, Fig. 1). Of the 241 papers, 5 (2\%) clearly defined the term (full definitions listed in the Supplementary Material, Table S8). Often, acceptance was used as a modifying adjective or was context-specific such as acceptable chance of survival for translocated cheetahs (Acinonyx jubatus) (Boast et al. 2016) or willingness to accept payment (de Leeuw et al. 2014).

Acceptance was measured in 13 papers of the 241 (5\%, Fig. 1) in which it appeared. Like definitions, measurements of acceptance were often situationally specific. Some papers compared observed data to acceptable parameters (Boast et al. 2016). Others spoke about willingness to accept payments (de Leeuw et al. 2014; Larson et al. 2015) or management actions (Infield et al. 1988; Kaltenborn 
Table 2 Attitudinal and behavioral measurements of tolerance, sorted into subcategories

\begin{tabular}{lll}
\hline Measurements of tolerance & \# of papers & Subject/s of study \\
\hline Attitudinal & 4 & Carnivores, elephants (Loxodonta africana), lions (Panthera leo), wildlife \\
Toward killing & 5 & Chimpanzees (Pan troglodytes), carnivores, mammals, predators \\
Toward damage-causing species & 1 & Wildlife \\
$\begin{array}{l}\text { Preferred population size } \\
\text { Desire for species on own property }\end{array}$ & 3 & Carnivores, wild dogs (Lycaon pictus) \\
Toward conservation actions & 4 & Elephants, wildlife \\
Behavioral & & \\
Killing behavior & 11 & Caracals (Caracal caracal), carnivores, cheetah (Acinonyx jubatus), elephants, hyenas, \\
& & jackals (Canis), leopards, lions, wild dogs \\
Intention to kill species in future & 8 & Carnivores, elephants, leopards, lions, monkeys, predators \\
Amount of loss before retaliatory killing & 4 & Carnivores, leopards, and cheetah \\
Behavior toward species (non-lethal) & 1 & Chimpanzees \\
Ecological & & Wildlife \\
Survival ability & 5 & Mammals \\
Population abundance or density & 1 &
\end{tabular}

et al. 2006; Larson et al. 2016) (Table S9). Of the 13 papers measuring acceptance, 3 also defined the term (Tables S8, S9).

Acceptance of a concept, event, or behavior was described as a conservation goal in 29 of 241 papers $(12 \%$, Fig. 1). Again, the form of acceptance was highly contextspecific. For example, some efforts aimed to increase acceptance for conservation management actions (Kideghesho et al. 2007; Alelign et al. 2017), some strove to meet "acceptable" parameters (Ashenafi et al. 2005; Rust and Marker 2013), and some sought sociopolitical acceptability (Treves et al. 2009). Few papers referring to acceptance as a goal either defined $(n=4)$ or measured $(n=4)$ it; in 2 papers, the authors both defined and measured the term (de Leeuw et al. 2014; Boast et al. 2016; Table S10).

\section{DISCUSSION}

The results of our systematic literature search highlighted that the key terms coexistence, tolerance, and acceptance were used in research that ranged across species and geographical locations. There was an increase in usage of these three terms over time. A definition of coexistence, tolerance and acceptance was often missing, and when these three concepts were described they often referred to conservation goals and measurements and lacked discussion on how to reach or testing these goals. In the following sections, we discuss the geographic and chronological distribution of coexistence, tolerance, and acceptance usage, highlight the problematic lack of unified terms and goals for these terms, and provide a pathway to move forward. We conclude providing some limitations to our research.

\section{Geography and species}

Studies on so-called conflict species (e.g., lions, elephants, carnivores in general) were common-potentially because of their focus on the psychological aspects of the human dimensions of conservation (e.g., attitudes and motivations) - and so were the countries in which these species are most often studied. The spatial variation we found (in particular, the higher number of studies conducted in Kenya, South Africa, Tanzania, Namibia, and Botswana than other African countries) is similar to that of research on human-lion conflict (Montgomery et al. 2018) and to studies on mitigation of livestock depredation by large carnivores (Miller et al. 2016). It is also possible that these countries are more frequently studied by wildlife conservationists, leading to an overrepresentation of them in literature, as has been shown subfields of conservation literature such as research on bushmeat consumption (van Velden et al. 2018), studies using camera-traps (Agha et al. 2018), papers on conflict management approaches in protected areas (Soliku and Schraml 2018), and communitybased conservation (Galvin et al. 2018). Alternately, our results could illustrate bias in our search terms.

\section{Chronological trends}

The use of all three key terms increased over time, from 1980 to 2018, a result that correlated with the findings of Nyhus (2016), who reported an exponential increase of the term "coexistence" between 1995 and 2015. Furthermore, 
the number of new publications and new journals has been increasing rapidly over time (Mund and Schmoch 2012; Haddaway et al. 2015). The focus on human dimensions in wildlife conservation has also grown over the past few decades (Bennett et al. 2017). The increase in key term usage over time may be due to increased interest, increased research publication, increased human dimensions research within conservation, and the increased evident need for conservation solutions that incorporate human behavior and needs, a mixture of these, or other unknown variables.

\section{Lack of consistent definition}

A precise lexicon is essential to any science. Conservation practitioners need common language to talk about problems they confront and the potential solutions to address those problems (Salafsky et al. 2008). When examining how the terms coexistence, tolerance, and acceptance are used in literature describing wildlife conservation in Africa, our primary finding was simply that the three terms were rarely and often vaguely defined. Few papers contained direct definitions of the terms, and those papers that did include a definition often lacked a consistent and/or comprehensive description. Only one paper defined coexistence as a stand-alone term (two defined it within phrases-Landscape of Coexistence and payments to encourage coexistence). Tolerance was defined in only 10 papers. No generalizable definition of acceptance (i.e., not contextspecific) was found in our literature search. For research results to be meaningful across all wildlife conservation approaches and geographical and cultural scales (BrownNuñez and Jonker 2008), clear definitions for coexistence, acceptance, and tolerance need to be utilized and made explicit in publications.

Another issue detected during our analysis was that tolerance for, and acceptance of, wildlife is often treated as analogous in wildlife conservation: both are frequently used to measure the ability and willingness of people to endure the negative aspects of living with wildlife and are described as essential to achieving or enabling coexistence. In our results, the two terms were often associated by measuring tolerance to make inferences about acceptance (Lindsey et al. 2013; Treves and Bruskotter 2014) and vice versa (Stein et al. 2010; Hazzah et al. 2013; Kansky et al. 2016). Other papers simply used the terms interchangeably (Enck et al. 2006; Higginbottom and Scott 2019). Bruskotter et al. (2012) argue that tolerance of, and acceptance for, wildlife represents the same construct in the context of wildlife conservation. Kansky et al. (2014) noted that the concept of tolerance is often used synonymously with attitude in human dimensions literature and Bruskotter et al. (2015) describes terms like 'tolerance' as jargon that may have a context-dependent meaning. While related, tolerance and acceptance have distinct dictionary definitions, as highlighted in the introduction of this contribution.

As a quantitative variable, tolerance was often indirectly defined by its measurements. Measures of tolerance varied between papers (Table 2) and consisted of both attitudinal and behavioral variables as well as ecological measurements. The diversity of measures used to assess tolerance supports is held up by Bruskotter et al. (2015), who offer evidence of consistency between attitudes and behavior in the context of tolerance for wildlife, and Treves (2012), who posits that tolerance may be evaluated by measuring attitudes or behaviors. These differences may be due to variation in intended outcomes, as is the case for assessing success in community-based conservation (Brooks et al. 2013). Selection of the most appropriate measure for tolerance within a specific conservation program context relies can be better informed if conservation publications include justification for measurement and the term definitions that guided research design.

\section{The problem of undefined terms and goals}

Our results highlight the already-established trend of setting human-wildlife coexistence as the end goal of conservation efforts (Chapron et al. 2014; Elliot et al. 2016; Fynn et al. 2016; Crespin and Simonetti 2019). Given the concept's lack of a consistent definition-as evidenced by our findings-it is expected and logical that researchers will associate different meanings with the termand have different ideas about what coexistence looks like and when it is achieved. For example, Crespin and Simonetti (2019) argue that land-sharing only works if coexistence is considered the end goal, explicitly contrasting coexistence with conflict-laden co-occurrence between humans and wildlife. However, other conservationists define the term as simply the physical co-occurrence of humans and wildlife in a landscape (Sitati et al. 2003; Dickman and Hazzah 2016). This discrepancy may be unproblematic when coexistence is specifically defined, yet this is not the case in current literature. This omission is a hindrance to clarity of how coexistence is used and understood for conservation and points to the need for inclusion of definition when communicating work aimed at coexistence as an end goal. The divergence becomes even more pronounced when we think about how human relationships with wildlife and their conservation vary across and within regions and cultures. Such lack of a common understanding of what coexistence means can lead to opposing and even conflicting conservation priorities and outcomes (Carter and Linnell 2016). In the United States, Treves et al. (2009) found that coexistence has different meanings to different people, as indicated by research on attitudes related to 
hunting and carnivores. Similarly, the term's definition varies among conservation efforts in Africa, illustrating that coexistence can look different depending on geography, culture, and/or species. Furthermore, although coexistence is a frequent conservation goal, it is rarely measured to determine and monitor the effect of a conservation intervention. Although ambiguous language may help researchers avoid imposing pre-conceived ideas onto a concept (Parathian et al. 2018), it is impossible to determine whether conservation efforts are indeed promoting or enabling coexistence if the goal itself is not measurable. Undefined goals set conservation projects up for failure because they make it difficult, or even impossible, to gage a project's success. It is possible to use other concepts as proxy measures for coexistence, yet they must be clearly identified and their relevance to human-wildlife coexistence must be discussed. Recently, several studies on large carnivore conservation have defined coexistence, either using Carter and Linnell's (2016) definition (Western et al. 2019) or crafting their own (Lamichane 2019). However, this increase in conceptualization of coexistence has been limited to large felids living in shared landscapes. Defining and operationalizing coexistence, while considering its multidimensionality and dynamic nature, are necessary to understanding conservation in the context of humanwildlife interactions (Carter and Linnell 2016; Frank et al. 2019).

Ideally, concepts in conservation should be clear, comprehensive, understandable to all practitioners, consistent, expandable, exclusive, and scalable (Salafsky et al. 2008), especially when these terms are used for setting conservation goals. Development of precise definitions for terms describing human-wildlife relationships would increase information-sharing and learning between conservation entities and could lead to more effective and efficient strategies for wildlife conservation. Also, definition of terms by authors within the context of their specific research may help standardize the concepts over time. Though variation in definition based on geographic and conservation issue is likely to persist, the inclusion of how coexistence, tolerance, and acceptance are conceptualized will enable future research to build on previous work within certain contexts. We are not arguing for the definition of terms to be given to research participants during data collection in all cases, as the role of conceptualization in research can vary between disciplines, but rather clearly reporting in publications the ways in which the term was used in each specific context and its implications. This expectation can be reinforced by journal editors, as requirements for publication in conservation journals evolve to improve the quality of social science (e.g., mandatory inclusion of ethics statements; Ibbett and Brittain 2020).

\section{Limitations}

The scope of this literature review was limited to published scientific papers, in English. Time and resources also constrained the review. Our search protocols bounded this review to publications from research conducted in Africa. It is possible that the trends that surfaced from our results do not reflect the use of coexistence, tolerance, and acceptance in other global contexts.

\section{Priorities for future research}

A singular and static definition for coexistence is unlikely to meet the needs of researchers working in varying contexts and dynamic conditions, the identification of its elements, such as the well-being of people living with wildlife and ethical handling of the wildlife involved (Glikman et al. 2019), can be a helpful starting point. Glikman et al. (2019) suggest defining coexistence from the perspective of the individuals and groups involved in wildlife conservation and those sharing the land with wildlife, to further our understanding of what the term coexistence means in different settings, with different species, across culture and sociopolitical contexts. These components of coexistence may be relative to dominant types of human-wildlife interactions within a setting. Examples of such components may be legitimate governance of shared grassland resources for livestock herders and ungulates (Mwangi and Ostrom 2009), livelihood security (Barua et al. 2013) related to livestock depredation by carnivores, or threat reduction for wildlife populations to persist (Crees et al. 2016). We call for conservationists and practitioners to prioritize building consensus on the components that comprise coexistence. This can be advanced through research that conceptualizes coexistence as appropriate for specific context and clear articulation of definition and measurement in research outputs.

Standards for publishing conservation social science could expect that research products include how key concepts like coexistence, acceptance, and tolerance were defined and conceptualized during the research process. The inclusion of definitions in research products will help interpretation of results, and in turn, applicability of findings to conservation practice. This shared effort to improve how studies are conducted and communicated will improve our collective understanding of coexistence, acceptance, and tolerance.

\section{CONCLUSIONS}

While our results reveal the need for a precise lexicon for wildlife conservation in Africa, this is something that 
should be consider applicable worldwide. Specifically, development of a unified understanding of what coexistence, tolerance, and acceptance mean in the context of human-wildlife interactions is necessary for the success of wildlife conservation and management interventions (Frank and Glikman 2019). However, it is unlikely that the lack of definition and clear conceptualization that we identified in this review is unique to these three terms. The field of wildlife conservation, and particularly the human dimensions of wildlife conservation, would benefit from both the establishment of precise characterization as well as context-specific definitions of social science terms when used by individual researchers and conservationists.

Acknowledgements At the time of writing, JAG was the associate director of the Community Engagement Team of the San Diego Zoo's Institute for Conservation Research. JK was supported by a research fellowship from Institute for Conservation Research. We would also like to thank the two anonymous reviewers for their helpful comments and suggestions.

\section{REFERENCES}

Agha, M., T. Batter, E.C. Bolas, A.C. Collins, D. Gomes da Rocha, C.M. Monteza-Moreno, S. Preckler-Quisquater, and R. Sollman. 2018. A review of wildlife camera trapping trends across Africa. African Journal of Ecology 56: 694-701.

Alelign, A., and M. Yonas. 2017. Community perceptions of grivet monkey crop depredation in the Ethiopian Highlands: Implications for primate conservation. Human-Wildlife Interactions 11: $175-181$.

Ashenafi, Z.T., T. Coulson, C. Sillero-Zubiri, and N. LeaderWilliams. 2005. Behaviour and ecology of the Ethiopian wolf (Canis simensis) in a human-dominated landscape outside protected areas. Animal Conservation 8: 113-121. https://doi. org/10.1017/S1367943005001952.

Barua, M., S.A. Bhagwat, and S. Jadhav. 2013. The hidden dimensions of human-wildlife conflict: Health impacts, opportunity and transaction costs. Biological Conservation 157: 309-316.

Benjamin-Fink, N., and B.K. Reilly. 2017. Conservation implications of wildlife translocations; the state's ability to act as conservation units for wildebeest populations in South Africa. Global Ecology and Conservation 12: 46-58.

Bennett, N.J. 2016. Using perceptions as evidence to improve conservation and environmental management. Conservation Biology 30: 582-592.

Bennett, N.J., R. Roth, S.C. Klain, K. Chan, P. Christie, D.A. Clark, G. Cullman, D. Curran, et al. 2017. Conservation social science: Understanding and integrating human dimensions to improve conservation. Biological Conservation 205: 93-108.

Boast, L.K., K. Good, and R. Klein. 2016. Translocation of problem predators: Is it an effective way to mitigate conflict between farmers and cheetahs Acinonyx jubatus in Botswana? Oryx 50: 537-544. https://doi.org/10.1017/S0030605315000241.

Bottrill, M., S. Cheng, R. Garside, S. Wongbusarakum, D. Roe, M.B. Holland, J. Edmond, and W.R. Turner. 2014. What are the impacts of nature conservation interventions on human well- being: a systematic map protocol. Environmental Evidence 3: 16. https://doi.org/10.1186/2047-2382-3-16.

Brooks, J., K.A. Waylen, and M.B. Mulder. 2013. Assessing community-based conservation projects: A systematic review and multilevel analysis of attitudinal, behavioral, ecological, and economic outcomes. Environmental Evidence 2: 2. https://doi. org/10.1186/2047-2382-2-2.

Brown-Nuñez, C., and J.A. Jonker. 2008. Attitudes toward wildlife and conservation in Africa: A review of survey research. Human Dimensions of Wildlife 13: 47-70. https://doi.org/10.1080/ 10871200701812936.

Bruskotter, J.T., and D.C. Fulton. 2012. Will hunters steward wolves? A comment on Treves and Martin. Society and Natural Resources 25: 97-102. https://doi.org/10.1080/08941920.2011. 622735.

Bruskotter, J.T., and R.S. Wilson. 2014. Determining where the wild things will be: Using psychological theory to find tolerance for large carnivores. Conservation Letters 7: 158-165.

Bruskotter, J.T., A. Singh, D.C. Fulton, and K. Slagle. 2015. Assessing tolerance for wildlife: Clarifying relations between concepts and measures. Human Dimensions of Wildlife 20: $255-270$.

Carpenter, L.H., D.J. Decker, and J.F. Lipscomb. 2000. Stakeholder acceptance capacity in wildlife management. Human Dimensions of Wildlife 5: 5-19.

Carter, N.H., and J.D.C. Linnell. 2016. Co-adaptation is key to coexisting with large carnivores. Trends in Ecology and Evolution 31: 575-578.

Chapron, G., P. Kaczensky, J.D.C. Linnell, M. von Arx, D. Huber, H. Andén, J.V. López-Bao, M. Adamec, et al. 2014. Recovery of large carnivores in Europe's modern human-dominated landscapes. Science 346: 1517-1519.

Child, B.A., J. Musengezi, G.D. Parent, and G.F.T. Child. 2012. The economics and institutional economics of wildlife on private land in Africa. Pastoralism: Research, Policy and Practice 2: 18. https://doi.org/10.1186/2041-7136-2-18.

Cortés-Avizanda, A., B. Martín-López, O. Ceballos, and H.M. Pereira. 2018. Stakeholders perceptions of the endangered Egyptian vulture: Insights for conservation. Biological Conservation 218: 173-180. https://doi.org/10.1016/j.biocon.2017.09. 028.

Crees, J.J., A.C. Collins, P.J. Stephenson, H.M. Meredith, R.P. Young, C. Howe, et al. 2016. A comparative approach to assess drivers of success in mammalian conservation recovery programs. Conservation Biology 30: 694-705.

Crespin, S.J., and J.A. Simonetti. 2019. Reconciling farming and wild nature: Integrating human-wildlife coexistence into the landsharing and land-sparing framework. Ambio 48: 131-138. https://doi.org/10.1007/s13280-018-1059-2.

de Leeuw, J.M., M.Y. Said, S. Kifugo, J.O. Ogutu, P. Osano, and J. de Leeuw. 2014. Spatial variation in the willingness to accept payments for conservation of a migratory wildlife corridor in the Athi-Kaputiei Plains, Kenya. Ecosystem Services 8: 16-24.

de Pinho, J.R., C. Grilo, R.B. Boone, K.A. Galvin, and J.G. Snodgrass. 2014. Influence of aesthetic appreciation of wildlife species on attitudes towards their conservation in Kenyan agropastoralist communities. PLoS ONE 9: e88842.

Decker, D.J., and K.G. Purdy. 1988. Toward a concept of Wildlife Acceptance Capacity in wildlife management. Wildlife Society Bulletin 16: 53-57.

Decker, D.J., S.J. Riley, and W.F. Siemer. 2012. Human Dimensions of Wildlife Management, 2nd ed. Baltimore: Johns Hopkins University Press.

Dickman, A.J., and L. Hazzah. 2016. Money, myths and man-eaters: Complexities of human-wildlife conflict. In Problematic Wildlife, ed. F. Angelici, 339-356. Cham: Springer. 
Dickman, A.J., E.A. Macdonald, and D.W. Macdonald. 2011. A review of financial instruments to pay for predator conservation and encourage human-carnivore coexistence. Proceedings of the National Academy of Sciences of the United States of America 108: 13937-13944.

Du Toit, J. 2002. Wildlife harvesting guidelines for community-based wildlife management: A southern African perspective. Biodiversity and Conservation 11: 1403-1416.

Elliot, A.J., and J.W. Fryer. 2013. The goal construct in psychology. In Handbook of Motivation Science, ed. J.Y. Shah and W.L. Gardner, 245-250. New York: Guilford Publications.

Elliot, A.J., and T.M. Thrash. 2001. Achievement goals and the hierarchical model of achievement motivation. Educational Psychology Review 12: 139-156.

Elliot, E.E., S. Vallance, and L. Molles. 2016. Coexisting with coyotes (Canis latrans) in an urban environment. Urban Ecosystems 19: 1335-1350.

Enck, J.W., D.J. Decker, S.J. Riley, J.F. Organ, L.H. Carpenter, and W.F. Siemer. 2006. Integrating ecological and human dimensions in adaptive management of wildlife-related impacts. Wildlife Society Bulletin 34: 698-705.

Eshete, G., G. Tesfay, H. Bauer, Z.T. Ashenafi, H. de Iongh, and J. Marino. 2015. Community resource uses and Ethiopian wolf conservation in Mount Abune Yosef. Environmental Management 56: 684-694. https://doi.org/10.1007/s00267-015-0529-6.

Frank, B. 2016. Human-wildlife conflicts, the need to include tolerance and coexistence: An introductory comment. Society and Natural Resources 29: 738-743.

Frank, B., J.A. Glikman, and S. Marchini. 2019. Human-Wildlife Interactions Turning Conflict into Coexistence. Cambridge: Cambridge University Press.

Fynn, R.W.S., D.J. Augustine, M.J.S. Peel, and M. de GarineWichatitsky. 2016. Strategic management of livestock to improve biodiversity conservation in African savannahs: A conceptual basis for wildlife-livestock coexistence. Journal of Applied Ecology 53: 388-397. https://doi.org/10.1111/13652664.12591.

Galvin, K.A., T.A. Beeton, and M.W. Luizza. 2018. African community-based conservation: A systematic review of social and ecological outcomes. Ecology and Society 23: 39. https://doi. org/10.5751/ES-10217-230339.

Glikman, J.A., B. Frank, and S. Marchini. 2019. Multifaceted approaches for turning conflict into coexistence. In HumanWildlife Interactions: Turning Conflict into Coexistence, ed. B. Frank, J.A. Glikman, and S. Marchini, 439-450. Cambridge: Cambridge University Press.

Gusset, M., M.J. Swarner, L. Mponwane, K. Keletile, and J.W. McNutt. 2009. Human-wildlife conflict in northern Botswana: Livestock predation by Endangered African wild dog Lycaon pictus and other carnivores. Oryx 43: 67-72.

Haddaway, N.R., P. Woodcock, B. Macura, and A. Collins. 2015. Making literature reviews more reliable through application of lessons from systematic reviews. Conservation Biology 29: $1596-1603$.

Hanaček, K., and B. Rodríguez-Labajos. 2018. Impacts of land-use and management changes on cultural agroecosystem services and environmental conflicts-A global review. Global Environmental Change 50: 41-59.

Harihar, A., P. Chanchani, R.K. Sharma, J. Vattakaven, S. Gubbi, B. Pandav, and B. Noon. 2013. Conflating 'co-occurrence' with 'coexistence'. Proceedings of the National Academy of Sciences of USA 110: e109.

Hazzah, L., M.B. Mulder, and L. Frank. 2009. Lions and Warriors: Social factors underlying declining African lion populations and the effect of incentive-based management in Kenya. Biological
Conservation 142: 2428-2437. https://doi.org/10.1016/j.biocon. 2009.06.006.

Hazzah, L., S. Dolrenrey, D. Kaplan, and L. Frank. 2013. The influence of park access during drought on attitudes toward wildlife and lion killing behaviour in Maasailand, Kenya. Environmental Conservation 40: 266-276.

Higginbottom, K., and N. Scott. 2019. Wildlife Tourism: A Strategic Destination Analysis. University Press.

Hill, C. 2017. Introduction. Complex problems: Using a biosocial approach to understanding human-wildlife interactions. In Understanding Conflicts About Wildlife: A Biosocial Approach, eds. C.M. Hill, A. Webber, N.E.C. Priston, 1-14. Oxford: Berghahn.

Hill, C., and A. Webber. 2010. Perceptions of nonhuman primates in human-wildlife conflict scenarios. American Journal of Primatology 72: 919-924. https://doi.org/10.1002/ajp.20845.

Hoare, R. 1995. Options for the control of elephants in conflict with people. Pachyderm 19: 54-63.

Hoare, R., and J.T. Du Toit. 1999. Coexistence between people and elephants in African savannas. Conservation Biology 13: 633-639.

Ibbett, H., and S. Brittain. 2020. Conservation publications and their provisions to protect research participants. Conservation Biology 34: 80-92.

Infield, M. 1988. Attitudes of a rural community towards conservation and a local conservation area in Natal, South Africa. Biological Conservation 45: 21-46.

Inskip, C., N. Carter, S. Riley, T. Roberts, and D. MacMillan. 2016. Toward human-carnivore coexistence: Understanding tolerance for tigers in Bangladesh. PLOS ONE 11: e0145913.

Kaltenborn, B.P., T. Bjerke, J.W. Nyahongo, and D.R. Williams. 2006. Animal preferences and acceptability of wildlife management actions around Serengeti National Park, Tanzania. Biodiversity and Conservation 15: 4633-4649. https://doi.org/10. 1007/s10531-005-6196-9.

Kansky, R., M. Kidd, and A.T. Knight. 2014. Meta-analysis of attitudes toward damage-causing mammalian wildlife. Conservation Biology 28: 924-938. https://doi.org/10.1111/cobi.12275.

Kansky, R., M. Kidd, and A.T. Knight. 2016. A wildlife tolerance model and case study for understanding human wildlife conflicts. Biological Conservation 201: 137-145.

Kideghesho, J.R., E. Røskaft, and B.P. Kaltenborn. 2007. Factors influencing conservation attitudes of local people in Western Serengeti, Tanzania. Biodiversity and Conservation 16: 2213-2230. https://doi.org/10.1007/s10531-006-9132-8.

Krippendorff, K. 2004. Content Analysis: An Introduction to Its Methodology. Thousand Oaks: SAGE.

Krippendorff, K. 2007. Computing Krippendorff's alpha reliability. Departmental Papers (ASC) 43. https://repository.upenn.edu/ asc_papers/43.

Lamichane, B. 2019. Living with the Large Carnivores: The interaction between humans, tigers and leopards in Chitwan National Park, Nepal. PhD Thesis, Leiden University.

Larson, D.M., E.F. Pienaar, and L.S. Jarvis. 2015. Wildlife conservation, labor supply and time values in rural Botswana. Environment and Development Economics 21: 135-157.

Larson, L.R., A.L. Conway, S.M. Hernandez, and J.P. Carrol. 2016. Human-wildlife conflict, conservation attitudes, and a potential role for citizen science in Sierra Leone, Africa. Conservation and Society 14: 205-217.

Lindsey, P.A., C.P. Havemann, R. Lines, L. Palazy, A.E. Price, T.A. Retief, T. Rhebergen, and C. Van der Waal. 2013. Determinants of persistence and tolerance of carnivores on Namibian ranches: Implications for conservation on southern African private lands. PLOS ONE 8: e52458. https://doi.org/10.1371/journal.pone. 0052458. 
Lischka, S.A., S.J. Riley, and B.A. Rudolph. 2008. Effects of impact perception on acceptance capacity for white-tailed deer. Journal of Wildlife Management 72: 502-509.

Lynch, M., and W. Gabriel. 1987. Environmental tolerance. The American Naturalist 129: 283-303.

Madden, F. 2004. Creating coexistence between humans and wildlife: Global perspectives on local efforts to address human-wildlife conflict. Human Dimensions of Wildlife 9: 247-257. https://doi. org/10.1080/10871200490505675.

McNutt, J.W., A.B. Stein, L.B. McNutt, and N.R. Jordan. 2017. Living on the edge: Characteristics of human-wildlife conflict in a traditional livestock community in Botswana. Wildlife Research 44: 546-557.

Miller, J.R.B., K.J. Stoner, M.R. Cejtin, T.K. Meyer, A.D. Middleton, and O.J. Schmitz. 2016. Effectiveness of contemporary techniques for reducing livestock depredations by large carnivores. Wildlife Society Bulletin 40: 806-815.

Mund, C., and U. Schmoch. 2012. The growth of science and database coverage. Scientometrics 93: 831-846.

Montgomery, R.A., C.F. Hoffman, E.D. Tans, and B. Kissui. 2018. Discordant scales and the potential pitfalls for human-carnivore conflict mitigation. Biological Conservation 224: 170-177.

Mwangi, E., and E. Ostrom. 2009. Top-down solutions: Looking up from East Africa's rangelands. Environment. Science and Policy for Sustainable Development 51: 34-45.

Myers, N., R.A. Mittermeier, C.G. Mittermeier, G.A.B. da Fonseca, and J. Kent. 2000. Biodiversity hotspots for conservation priorities. Nature 403: 853-858.

Nyhus, P.J. 2016. Human-wildlife conflict and coexistence. Annual Review of Environment and Resources 41: 143-171.

Oriol-Cotterill, A., D.W. Macdonald, M. Valeix, S. Ekwanga, and L.G. Frank. 2015. Spatiotemporal patterns of lion space use in a human-dominated landscape. Animal Behavior 101: 27-39.

Parathian, H.E., M.R. McLennan, C.M. Hill, A. Frazão-Moreira, and K.J. Hockings. 2018. Breaking through disciplinary barriers: Human-wildlife interactions and multispecies ethnography. International Journal of Primatology 39: 749-775. https://doi. org/10.1007/s10764-018-0027-9.

Peterson, M.N., J.L. Birckhead, K. Leong, M.J. Peterson, and T.R. Peterson. 2010. Rearticulating the myth of human-wildlife conflict. Conservation Letters 3: 74-82.

Redpath, S.M., S. Bhatia, and J. Young. 2015. Tilting at wildlife: Reconsidering human-wildlife conflict. Oryx 49: 222-225.

Riley, S.J., and D.J. Decker. 2000. Wildlife stakeholder acceptance capacity for cougars in Montana. Wildlife Society Bulletin 28: 931-939.

Roe, D., M. Day, F. Booker, W. Zhou, S. Allebone-Webb, N. Kümpel, N.A.O. Hill, J. Wright, et al. 2015. Are alternative livelihood projects effective at reducing local threats to specified elements of biodiversity and/or improving or maintaining the conservation status of those elements? Environmental Evidence 4: 22. https://doi.org/10.1186/s13750-015-0048-1.

Rust, N.A., and L.L. Marker. 2013. Cost of carnivore coexistence on communal and resettled land in Namibia. Environmental Conservation 41: 45-53. https://doi.org/10.1017/ S0376892913000180.

Salafsky, N., D. Salzer, A.J. Stattersfield, C. Hilton-Taylor, R. Neugarten, S.H.M. Butchart, B. Collen, N. Cox, et al. 2008. A standard lexicon for biodiversity conservation: Unified classifications of threats and actions. Conservation Biology 22: 897-911.

Sitati, N.W., M.J. Walpole, R.J. Smith, and N. Leader-Williams. 2003. Predicting spatial aspects of human-elephant conflict. Journal of Applied Ecology 40: 667-677.

Soliku, O., and U. Schraml. 2018. Making sense of protected area conflicts and management approaches: A review of causes, contexts and conflict management strategies. Biological Conservation 222: 136-145. https://doi.org/10.1016/j.biocon.2018. 04.011.

Songhurst, A. 2017. Measuring human-wildlife conflicts: Comparing insights from different monitoring approaches. Wildlife Society Bulletin 41: 351-361.

St John, F.A.V., A.M. Keane, G. Edwards-Jones, L. Jones, R.W. Yarnell, and J.P.G. Jones. 2012. Identifying indicators of illegal behaviour: Carnivore killing in human-managed landscapes. Proceedings of the Royal Society B: Biological Sciences 279: 804-812. https://doi.org/10.1098/rspb.2011.1228.

Stein, A.B., T.K. Fuller, D.T. Damery, L. Sievert, and L.L. Marker. 2010. Farm management and economic analysis of leopard conservation in north-central Namibia. Animal Conservation 13: 419-427. https://doi.org/10.1111/j.1469-1795.2010.00364.x.

Tabossi, P. 1988. Effects of context on the immediate interpretation of unambiguous nouns. Journal of Experimental Psychology 14: $153-162$.

Tchamba, M.N. 1995. The problem elephants of Kaele: A challenge for elephant conservation in northern Cameroon. Pachyderm 19: 26-32.

Tessema, M.E., R.J. Lilieholm, Z.T. Ashenafi, and N. LeaderWilliams. 2010. Community attitudes toward wildlife and protected areas in Ethiopia. Society and Natural Resources 23: 489-506. https://doi.org/10.1080/08941920903177867.

Treves, A. 2012. Tolerant attitudes reflect an intent to steward: A reply to Bruskotter and Fulton. Society and Natural Resources 25: 103-104.

Treves, A., and J. Bruskotter. 2014. Ecology. Tolerance for predatory wildlife. Science 344: 476-477.

Treves, A., R.B. Wallace, and S. White. 2009. Participatory planning of interventions to mitigate human-wildlife conflicts. Conservation Biology 23: 1577-1587. https://doi.org/10.1111/j.15231739.2009.01242.x.

UNEP-WCMC. 2016. The State of Biodiversity in Africa: A Mid-term Review of Progress Towards the Aichi Biodiversity Targets. Cambridge: UNEP-WCMC.

van Velden, J., K. Wilson, and D. Biggs. 2018. The evidence for the bushmeat crisis in African savannas: A systematic quantitative literature review. Biological Conservation 221: 345-356.

Western, G., D.W. Macdonald, A.J. Loveridge, and A.J. Dickman. 2019. Creating landscapes of coexistence: Do conservation interventions promote tolerance of lions in human-dominated landscapes? Conservation and Society 17: 204-217.

Publisher's Note Springer Nature remains neutral with regard to jurisdictional claims in published maps and institutional affiliations.

\section{AUTHOR BIOGRAPHIES}

Jillian Knox is pursuing a J.D. at Sa ndra Day O'Connor College of Law at Arizona State University. At the time of this research, she was a Research Associate in the Community Engagement Team of the San Diego Zoo's Institute for Conservation Research.

Address: Institute for Conservation Research, San Diego Zoo, 15600 San Pasqual Valley Road, Escondido, CA 92027, USA.

Address: Arizona State University's Sandra Day O'Connor College of Law, 111 E Taylor Street, Phoenix, AZ 85287, USA.

e-mail: jillianknox4@gmail.com

Kirstie Ruppert is a Researcher at the San Diego Zoo Institute for Conservation Research, where her work focuses on social science to understand the human dimensions of wildlife and engaging with communities to integrate research findings into conservation strategies.

Address: Institute for Conservation Research, San Diego Zoo, 15600 
San Pasqual Valley Road, Escondido, CA 92027, USA.

Address: Department of Wildlife, Fisheries, and Conservation Biology, University of Maine, Orono, ME 04469, USA.

e-mail: KRuppert@sandiegozoo.org

Beatrice Frank is the Social Science Specialist of Regional Parks, Capital Regional District of Victoria, Canada. Her research and work focus on the human dimensions of wildlife and protected areas, with an emphasis on engaging the public in decision-making and fostering human-wildlife coexistence.

Address: Capital Regional District-Regional Parks Canada, Victoria, BC V9B2Z8, Canada.

e-mail: frankbea@hotmail.com

Carly C. Sponarski is an Associate Professor at the University of Maine. Her research interests include social psychological approaches to understanding human-wildlife relationships in order to support conservation.
Address: Department of Wildlife, Fisheries, and Conservation Biology, University of Maine, Orono, ME 04469, USA.

e-mail: carlycs@maine.edu

Jenny Anne Glikman $(\triangle)$ is a senior researcher at the Instituto de Estudios Sociales Avanzados (IESA-CSIC), Spain. As a social scientist, she focuses on understanding the relationships between humans and wildlife. Her work ranges from studying and addressing human-wildlife interactions, to exploring various aspects of local consumers of wildlife products in several countries.

Address: Institute for Conservation Research, San Diego Zoo, 15600 San Pasqual Valley Road, Escondido, CA 92027, USA.

Address: Instituto de Estudios Sociales Avanzados (IESA-CSIC), Campo Santo de los Mártires 7, 14004 Córdoba, Spain.

e-mail: jaopy@hotmail.com 